\title{
Wear-life analysis of 6000 deep groove ball bearings
}

\author{
Guangwei Yu' ${ }^{1}$ * Wei Xia ${ }^{1}$, Zhuoyuan Song ${ }^{2}$, Rui Wu ${ }^{1}$, Siling Wang ${ }^{1}$ \\ ${ }^{1}$ School of Mechanical Engineering and Automation, Shanghai University, Shanghai 200072, China \\ ${ }^{2}$ Department of Mechanical and Aerospace Engineering, University of Florida, Gainesville, FL, \\ USA
}

Email: m18800205515@163.com

Keywords: deep groove ball bearing; quasi-dynamics; permissible wear; wear-life

\begin{abstract}
A quasi-dynamic method is proposed to evaluate the characteristics of ball bearings including pressure distribution over the contact area between the ball and the raceway; sliding velocity distribution and lubrication parameters. Based on the Archard wear equation, the permissible wear extent is confirmed, and a mathematical model for wear-life analysis is then presented for 6000 deep groove ball bearings with the axial loads. The effects of axial loads, rotating speed and structural parameters on wear characteristics of bearings are analyzed, and some conclusions are drawn. Based on the proposed mathematical model, wear-life of a bearing decreases with the increase of the axial load. As the rotational speed of the inner ring increases, the wear-life of the bearing decreases accordingly. The wear-life of the bearing exhibits nearly-linear increment as the groove curvature of the inner ring increases.
\end{abstract}

\section{INTRODUCTION}

Wear-life is a critical property for deep groove ball bearings. Existing methods for wear-life are not yet comprehensive due to the complexity of the wear effects of rolling bearings [1]. Currently, wear-life estimate of rolling bearings is mainly based on the wear time analysis given by FAG in 1964. FAG performed statistical classification over the operational conditions of more than 7000 rolling bearings from different equipment and obtained their wear-life through Weibull distribution for their operation time before failure. Based on their analysis, one can obtain an estimate of the wear-life of a bearing given its application on an equipment [2].

Friction and wear are complex processes. Based on existing literature, more than 300 variations of wear calculation have been proposed [3]. Amontons and Coulomb proposed the law of friction: the friction is proportional to the positive pressure [4]. Archard proposed the law of wear: the material wear coefficient is proportional to the load and the sliding distance [5].

Based on Archard's wear model, we first determine the permissible wear of the bearing through quasi-dynamic analyses assuming only axial loads exist. A mathematical model of wear-life of deep groove ball bearings is then proposed to analyze the effects of axial loads, rotational speeds, and structural parameters on the wearing characteristics of the bearings.

Under common, mid-speed operations, the ball typically undergoes rolling without slipping in the race.

Therefore, the proposed wear model is based on the following assumptions:

(1) All friction-including materials are isotropic and their friction properties remain invariant in the analysis period;

(2) Surface roughness of the components interest remains constant and the post-wear profiles of both inner and outer races remain circular. 


\section{QUASI-DYNAMIC ANALYSIS OF ROLLING BEARINGS}

\subsection{Revolution, rotation and spin of rolling elements}

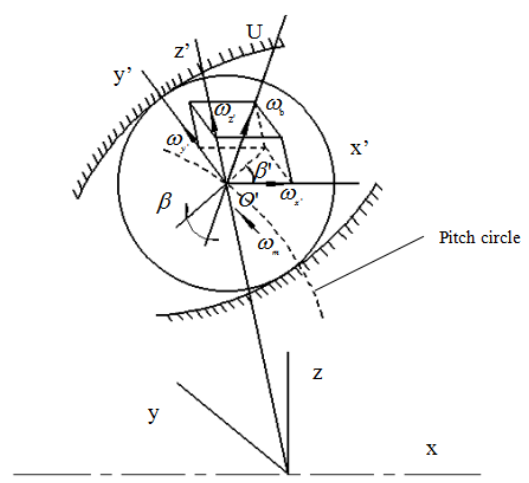

Fig. 1 Illustration of three-dimensional ball movement.

The three-dimensional rotation of the ball is shown in Fig.1. ' $\{\mathrm{x}, \mathrm{y}, \mathrm{z}\}$ ' is a inertial frame, and ' $\left\{x^{\prime}, y^{\prime}, z\right.$ ' $\}$ ' is the local coordinate with its origin located at the center of the ball. Axis $x$ ' is parallel to axis $\mathrm{x}$, and the coordinate system rotates about axis $\mathrm{x}$ at the revolution speed of the ball. O' $\mathrm{U}$ is the rotation axis of the ball. The three components of the angular velocity $\mathrm{w}_{\mathrm{b}}$ are $\mathrm{w}_{\mathrm{bx}}, \mathrm{w}_{\mathrm{by}}$, and, $\mathrm{w}_{\mathrm{bz}}$, respectively:

$$
\omega b=\left(\omega b x^{\prime 2}+\omega b y^{\prime^{2}}+\omega b z^{\prime^{2}}\right)^{1 / 2},
$$

among which,

$$
\begin{aligned}
& \omega_{x^{\prime}}=\omega_{b} \cos \beta \cdot \cos \beta^{\prime}, \\
& \omega_{y^{\prime}}=\omega_{b} \cos \beta \cdot \sin \beta^{\prime}, \\
& \omega_{z^{\prime}}=\omega_{b} \sin \beta .
\end{aligned}
$$

At any point $\left(\mathrm{x}_{0}, \mathrm{y}_{\mathrm{o}}\right)$ in the contact area, the speed of the outer race relative to the ball is

$$
\begin{gathered}
u_{y o}=-\frac{d_{m} \omega_{o}}{2}+\left\{\left(R_{o}^{2}-X_{o}^{2}\right)^{1 / 2}-\left(R_{o}^{2}-a_{o}^{2}\right)^{1 / 2}+\right. \\
\left.\left[\left(\frac{D_{w}}{2}\right)^{2}-a_{o}^{2}\right]^{1 / 2}\right\} \times\left(\frac{\omega_{b}}{\omega_{o}} \cos \beta \cos \beta^{\prime} \cos \alpha_{o},\right. \\
\left.+\frac{\omega_{b}}{\omega_{o}} \sin \beta \sin \alpha_{o}-\cos \alpha_{o}\right) \omega_{o} \\
u_{x o}=-\left\{\left(R_{o}^{2}-X_{o}^{2}\right)^{1 / 2}-\left(R_{o}^{2}-a_{o}^{2}\right)^{1 / 2}+\right. \\
\left.\left[\left(\frac{D_{w}}{2}\right)^{2}-a_{o}^{2}\right]^{1 / 2}\right\} \omega_{o}\left(\frac{\omega_{b}}{\omega_{o}} \cos \beta \sin \beta^{\prime}\right) .
\end{gathered}
$$

The component of the angular velocity (spin motion) in the normal direction of the contact surface of the ball and outer ring:

$$
\begin{gathered}
\omega_{s o}=\left(\frac{\omega_{b}}{\omega_{o}} \cos \beta \cos \beta^{\prime} \sin \alpha_{o}-\frac{\omega_{b}}{\omega_{o}} \sin \beta \cos \alpha_{o},\right. \\
\left.-\sin \alpha_{0}\right) \omega_{o}
\end{gathered}
$$

where,

$$
\frac{\omega_{b}}{\omega_{o}}=\frac{d_{m} / 2+r_{o}{ }^{\prime} \cos \alpha_{o}}{r_{o}{ }^{\prime}\left(\cos \beta \cos \beta^{\prime} \cos \alpha_{o}+\sin \beta \sin \alpha_{o}\right)} \text {. }
$$

Similarly, at any point $\left(\mathrm{x}_{0}, \mathrm{y}_{\mathrm{o}}\right)$ in the contact area, the speed of the inner race relative to the ball is:

$$
\begin{aligned}
& u_{y i}=-\frac{d_{m} \omega_{i}}{2}-\left\{\left(R_{i}{ }^{2}-X_{i}{ }^{2}\right)^{1 / 2}-\left(R_{i}{ }^{2}-a_{i}{ }^{2}\right)^{1 / 2}+\right. \\
& \left.\left[\left(\frac{D_{w}}{2}\right)^{2}-a_{i}{ }^{2}\right]^{1 / 2}\right\} \times\left(\frac{\omega_{b}}{\omega_{i}} \cos \beta \cos \beta^{\prime} \cos \alpha_{i}+\right. \\
& \left.\frac{\omega b}{\omega_{i}} \sin \beta \sin \alpha_{i}-\cos \alpha_{i}\right) \omega_{i}
\end{aligned}
$$




$$
\begin{aligned}
& u_{x i}=\left\{\left(R_{i}^{2}-X_{i}^{2}\right)^{1 / 2}-\left(R_{i}^{2}-a_{i}^{2}\right)^{1 / 2}+\right. \\
& \left.\left.\left[\left(\frac{D_{w}}{2}\right)^{2}-a_{i}^{2}\right]^{1 / 2}\right\} \omega \frac{\omega_{b}}{\omega_{i}} \cos \beta \sin \beta^{\prime}\right), \\
& \begin{array}{c}
\omega_{s i}=\left(\frac{\omega b}{\omega_{i}} \cos \beta \cos \beta^{\prime} \sin \alpha_{i}+\frac{\omega b}{\omega_{i}} \sin \beta \cos \alpha_{i}\right. \\
\left.\quad+\sin \alpha_{i}\right) \omega_{i} \\
-d_{m} / 2+r_{i}{ }^{\prime} \cos \alpha_{i}
\end{array} \\
& \frac{\omega b}{\omega i}=\frac{r_{i}\left(\cos \beta \cos \beta^{\prime} \cos \alpha_{i}+\sin \beta \sin \alpha_{i}\right)}{r^{\prime}}
\end{aligned}
$$

According to the Hertz theory, under contact loads, the contact area between the ball and the circle race is a oval surface. Hertz defines the Hertz contact radius $\mathrm{R}$ as [6]

$$
R_{n}=\frac{2 f_{n} D_{w}}{2 f_{n}+1} \quad(n=i, o) .
$$

If the outer race is fixed, the center of the ball rotates around the origin of the fixed coordinate system at the rotating speed of $\mathrm{w}_{\mathrm{m}}=-\mathrm{w}_{\mathrm{o}}$. The inner ring rotates at an absolute angular velocity $\mathrm{w}=\mathrm{w}_{\mathrm{m}}+\mathrm{w}_{\mathrm{i}}$. Therefore, the relative angular velocity $\mathrm{w}_{\mathrm{o}}, \mathrm{w}_{\mathrm{i}}$ and the angular velocity $\mathrm{w}_{\mathrm{b}}$ of the ball can be obtained as [7]

$$
\begin{gathered}
\omega_{i}=\frac{\omega}{1+\frac{r_{o}^{\prime}\left(d_{m} / 2-r_{i}^{\prime} \cos \alpha_{i}\right)\left(\cos \beta \cos \beta^{\prime} \cos \alpha_{o}+\sin \beta \sin \alpha_{o}\right)}{r_{i}^{\prime}\left(d_{m} / 2+r_{o}^{\prime} \cos \alpha_{o}\right)\left(\cos \beta \cos \beta^{\prime} \cos \alpha_{i}+\sin \beta \sin \alpha_{i}\right)}} \\
\omega_{b}=\frac{-\omega}{\frac{r_{o}{ }^{\prime}\left(\cos \beta \cos \beta^{\prime} \cos \alpha_{o}+\sin \beta \sin \alpha_{o}\right)}{\left(d_{m} / 2+r_{o}{ }^{\prime} \cos \alpha_{o}\right)}} \\
+\frac{r_{i}^{\prime}\left(\cos \beta \cos \beta^{\prime} \cos \alpha_{i}+\sin \beta \sin \alpha_{i}\right)}{\left(d_{m} / 2-r_{i}{ }^{\prime} \cos \alpha_{i}\right)}
\end{gathered}
$$

\subsection{Force analysis of deep groove ball bearings}

1) Contact deformation and contact load of balls and inner and outer rings

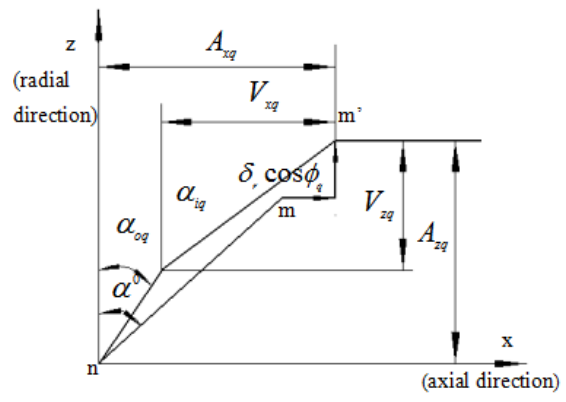

Fig. 2 Distance between the center of any ball and the center of the inner and outer rings

It can be seen from Fig. 2 that the distance along the axial direction and the radial direction between the center $m$ ' of the inner groove curvature and any ball position $\Phi_{q}$ under load can be presented as

$$
\begin{aligned}
& A_{x q}=B D_{w} \sin \alpha^{0}+\delta_{a}, \\
& A_{z q}=B D_{w} \sin \alpha^{0} .
\end{aligned}
$$

The contact deformation between the ball and the inner and outer rings can be presented as $\delta_{i q}=\left(V_{x q}{ }^{2}+V_{z q}{ }^{2}\right)^{1 / 2}-\left(f_{i}-0.5\right) D_{w}$, $\delta_{o q}=\left[\left(A_{x q}-V_{x q}\right)^{2}+(A z q-V z q)^{2}\right]^{1 / 2}-(f o-0.5) D_{w} \cdot(20)$

The position parameters of the q-th ball's center are $V_{\mathrm{xq}}$ and $\mathrm{V}_{\mathrm{zq}}$, which are related to the deformation and the rotating speed of the bearing. The contact angle of the q-th ball and the inner and outer rings is shown in Fig. 2, where

$$
\cos \alpha_{o q}=\frac{V_{z q}}{\left(f_{i}-0.5\right) D_{w}+\delta_{i q}},
$$




$$
\begin{aligned}
& \sin \alpha_{o q}=\frac{V_{x q}}{\left(f_{i}-0.5\right) D_{w}+\delta_{i q}}, \\
& \cos \alpha_{i q}=\frac{A_{z q}-V_{z q}}{\left(f_{i}-0.5\right) D_{w}+\delta 0 q}, \\
& \sin \alpha_{i q}=\frac{A_{x q}-V_{x q}}{\left(f_{i}-0.5\right) D_{w}+\delta 0 q} .
\end{aligned}
$$

Deformation compatibility condition is

$$
\begin{aligned}
& \left(A_{x q}-V_{x q}\right)^{2}+\left(A_{z q}-V_{z q}\right)^{2}-\left[\left(f_{i}-0.5\right) D+\delta_{i q}\right]^{2}=0,(25) \\
& \left(V_{x q}\right)^{2}+\left(V_{z q}\right)^{2}-\left[\left(f_{o}-0.5\right) D+\delta_{o q}\right]^{2}=0 .
\end{aligned}
$$

The contact load between the ball and the inner and outer rings can be calculated as

$$
\begin{aligned}
& Q_{i q}=K_{i q} \delta_{i q}{ }^{2 / 3}, \\
& Q_{o q}=K_{o q} \delta_{o q}{ }^{2 / 3} .
\end{aligned}
$$

2) Force and basic equations of the bearing

From Fig. 2, when the forces in horizontal and vertical directions of the ball are considered, the balance equations are

$Q_{i q} \sin \alpha_{i q}-Q_{o q} \sin \alpha_{o q}-$

$\frac{M_{g q}}{D_{w}}\left(\lambda_{i q} \cos \alpha_{i q}-\lambda_{o q} \cos \alpha_{o q}\right)=0$,

$Q_{i q} \cos \alpha_{i q}-Q_{o q} \cos \alpha_{o q}+$

$\frac{M_{g q}}{D_{w}}\left(\lambda_{i q} \sin \alpha_{i q}-\lambda_{o q} \sin \alpha_{o q}\right)+F_{c q}=0$.

where,

$$
\begin{aligned}
& F_{c q}=\frac{1}{2} m d_{m} \omega^{2}\left(\frac{\omega m}{\omega}\right)_{q}{ }^{2}, \\
& M_{g q}=J\left(\frac{\omega b}{\omega}\right)_{q}\left(\frac{\omega m}{\omega}\right)_{q} \omega^{2} \sin \beta .
\end{aligned}
$$

Under the condition of the control of the outer raceway [8], $\lambda_{\text {iq }}=0, \lambda_{\text {oq }}=2$.

The balance equation of the inner ring is

$$
F_{a}-\sum_{q=1}^{2}\left(Q_{i q} \sin \alpha_{i q}-F_{i q} \cos \alpha_{i q}\right)=0 \text {. }
$$

The unknown parameters $\delta_{\mathrm{iq}}, \delta_{\mathrm{oq}}, \mathrm{V}_{\mathrm{xq}}, \mathrm{V}_{\mathrm{zq}}$ can firstly be solved by Newton - Raphson iteration method using the set of equations (28), (29), (30) and (31) for a given $\delta_{\mathrm{a}}$. After obtaining the values of $\delta_{\mathrm{iq}}, \delta_{\mathrm{oq}}, \mathrm{V}_{\mathrm{xq}}$ and $\mathrm{V}_{\mathrm{zq}}$, the value of $\delta_{\mathrm{a}}$ can be obtained from equation (34). Then $\delta_{\mathrm{iq}}, \delta_{\mathrm{oq}}, \mathrm{V}_{\mathrm{xq}}, \mathrm{V}_{\mathrm{zq}}$ can be calculated repeatedly, until the accuracy requirement of $\delta_{a}$ is satisfied. Such a rursivive process is illustrated by a flow chart shown in Fig. 3.

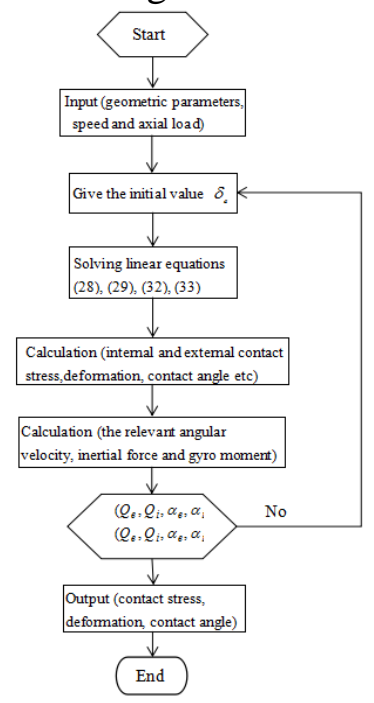

Fig. 3 Flow chart for calculating performance of deep groove ball bearings 


\section{WEAR-LIFE MODEL OF DEEP GROOVE BALL BEARINGS}

Archard's wear model [5] is adopted in the proposed method $V=K_{s} \frac{Q L}{H}$,

where, $\mathrm{V}$ is the loss of the material volume, $\mathrm{K}_{\mathrm{s}}$ is the wear coefficient, $\mathrm{H}$ is the Brinell hardness of the material. $\mathrm{Q}$ is the normal load on the contact surface, and $\mathrm{L}$ is the sliding distance.

According to Liu et al. [9], the parameter oil film $\Lambda$ has a graph relation with the Archard wear coefficient $\mathrm{K}_{\mathrm{s}}$. The expression for $\Lambda$ can be found as [10],

$$
\Lambda=\frac{h}{\sqrt{R_{q r}{ }^{2}+R_{q b}{ }^{2}}},
$$

where, $\mathrm{R}_{\mathrm{qr}}$ and $\mathrm{R}_{\mathrm{qb}}$ are the RMS of the surface roughness of the race and the rolling elements, respectively; $h$ is the film oil thickness.

Therefore, different $\Lambda$ can be found according to the Archard wear coefficient $K_{s}$. For the mathematical model proposed in the paper, the lubricating status is boundary lubrication, such that $\Lambda=0.85$, and $\mathrm{K}_{\mathrm{s}}=1.77 \times 10^{-8}$.

For the ball-ring interaction, the load and sliding speed vary substantially across the elliptical contact area. Therefore, a more accurate calculation can be obtained by substituting.

$$
Q u=\iint P_{H} u d x d y \text {, }
$$

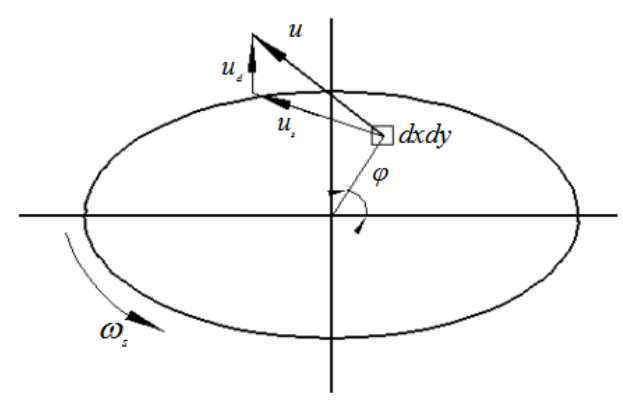

Fig. 4 Distribution of pressure and sliding velocity across the contact area

The sliding distribution across the contact area is shown in Fig. 4 where the slip and gyro rotation of the ball are ignored. In Fig. $4, \mathrm{u}_{\mathrm{s}}$ is the sliding speed included by the self-spin component; $\mathrm{u}_{\mathrm{d}}$ is the differential sliding speed as the result of the difference in radius of rotation between the ball and rings at the location of contact. According to a fore mentioned kinematics analysis, $\mathrm{u}_{\mathrm{d}}$ and $\mathrm{u}_{\mathrm{s}}$ can be calculated as

$$
u d=-\frac{d m \omega_{i}}{2}\left\{1-\frac{1-\left(R_{j}{ }^{2}-x_{j}^{2}\right)^{1 / 2}-\left(R_{j}{ }^{2}-a_{j}^{2}\right)^{1 / 2}+\left[\left(\frac{D_{w}}{2}\right)^{2}-a_{j}^{2}\right]^{1 / 2}}{r_{j}{ }^{\prime}}\right\},
$$

where

$$
r_{j}^{\prime}=R_{j}-\left(R_{j}^{2}-a_{j}^{2}\right)^{1 / 2}+\left[\left(\frac{D_{w}}{2}\right)^{2}-a_{j}^{2}\right]^{1 / 2} \quad(j=i, o),
$$

and

$$
u_{s}=\sqrt{x^{2}+y^{2}} \omega_{s} .
$$

Therefore, Qu can be found as

$$
\begin{gathered}
Q u=\frac{3 Q_{\max }}{2 \pi a b} \int_{-a}^{+a} \int_{-b\left[1-(x / a)^{2}\right]^{1 / 2}}^{+b\left[-(x / 2)^{2}\right.}\left[1-\left(\frac{x}{a}\right)^{2}-\left(\frac{y}{b}\right)^{2}\right]^{1 / 2} \\
\cdot \sqrt{\left(y \omega_{s}\right)^{2}+\left(x \omega_{s}+u_{d}\right)^{2}} d y d x
\end{gathered} .
$$

The value of Qu for the inner race and the outer race can be computed by using MATHCAD [11].

To consider the wear on the surface of the rolling element and races, the calculation can be transformed to

$$
V=K_{s} \frac{Q Z L}{H}=K_{s} \frac{Q Z u t}{H},
$$

where $t$ is the total wear time during the whole operation period. 
The derivation of equation (42) is the wear rate $\mathrm{W}_{\mathrm{m}}$. It can be presented as $W_{m}=K_{s} \frac{Q Z u}{H}$.

The parameter $\Delta \mathrm{r}$ is set to be the permissible radial clearance increment, the value which is typically selected as $20 \%$ of the initial clearance [12]. The permissible volume of wear, V, can then be deduced according to the geometrical dimensions of the bearing.

$$
V_{i(j)}=\frac{\Delta r}{\left(\frac{1}{2 \pi a_{i(o)}\left(d_{m} \pm D_{w} \cos \alpha_{i(o)}\right)}+\frac{2}{Z \pi D_{w}{ }^{2}}\right)} \text {. }
$$
(44).

A negative sign is applied for the inner ring and the positive sign is for the outer ring for equation

So the operating lifetime can be presented as

$$
t=\frac{\Delta r}{\left(\frac{1}{2 \pi a_{i(o)}\left(d_{m} \pm D_{w} \cos \alpha_{i(o)}\right)}+\frac{2}{Z \pi D_{w}{ }^{2}}\right) \cdot\left(\frac{K_{S} Z Q u}{3 H}\right) .}
$$

\section{ANALYSIS OF WEAR CHARACTERISTICS OF DEEP GROOVE BALL BEARINGS}

Here we take the 6000 deep groove ball bearings as an example. The influences of different axial loads, rotating speeds and the groove curvature of the inner and outer rings on the wear-rate and the wear-life of the bearings are investigated. Parameters of the bearings are presented in Table I.

Table I. BEARING PARAMETERS USED FOR ANALYSES

\begin{tabular}{|c|c|c|c|}
\hline Name & Value & Name & Value \\
\hline Model & 6000 & Number of balls & 7 \\
\hline $\begin{array}{c}\text { Inside diameter } \\
(\mathrm{mm})\end{array}$ & 10 & Diameter of balls (mm) & 4.763 \\
\hline $\begin{array}{c}\text { Outside diameter } \\
(\mathrm{mm})\end{array}$ & 26 & $\begin{array}{c}\text { Diameter of the inner } \\
\text { raceway (mm) }\end{array}$ & 4.858 \\
\hline Width (mm) & 8 & $\begin{array}{c}\text { Diameter of the outer } \\
\text { raceway (mm) }\end{array}$ & 5.144 \\
\hline Contact angel ( $\left.{ }^{\circ}\right)$ & $\begin{array}{c}10.5- \\
14.5\end{array}$ & $\begin{array}{c}\text { Radius coefficient of the } \\
\text { groove curvature of inner } \\
\text { ring }\end{array}$ & 0.51 \\
\hline $\begin{array}{c}\text { Diameter of the } \\
\text { pitch circle (mm })\end{array}$ & 17.8 & $\begin{array}{c}\text { Radius coefficient of the } \\
\text { groove curvature of outer } \\
\text { ring }\end{array}$ & 0.54 \\
\hline
\end{tabular}

\subsection{Influence of axial loads}

When the lubrication and other conditions are fixed and the rotating speed is $10000 \mathrm{rpm}$, the relation between the axial load and the wear characteristics is shown in Fig. 5 and Fig. 6.

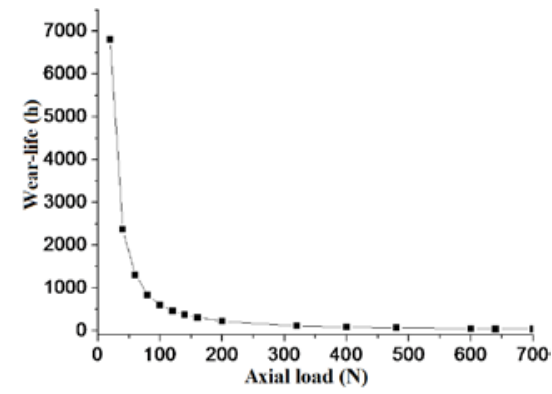

Fig. 5 Relationship between the axial loads and the wear-life 


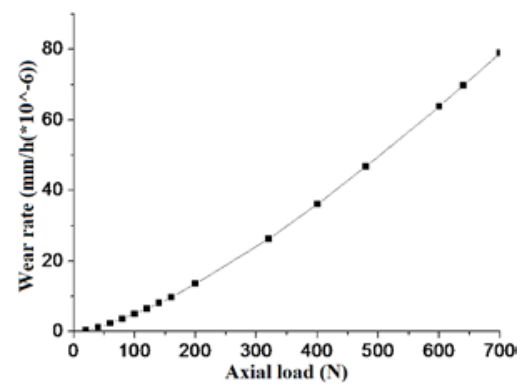

Fig. 6 Relationship between the axial loads and the wear-rate

It can be seen from Fig. 5 and Fig. 6, the wear-life decreases with the increase of axial loads. With the gradual increase of the load, the slope of wear-life curve is getting smaller, while the wear-rate increases with the increase of axial loads.

\subsection{Influence of rotating speeds}

When lubrication and other conditions are fixed and the axial load is $20 \mathrm{~N}$, the relation of the rotating speed and wear characteristics is shown in Fig. 7 and Fig. 8.

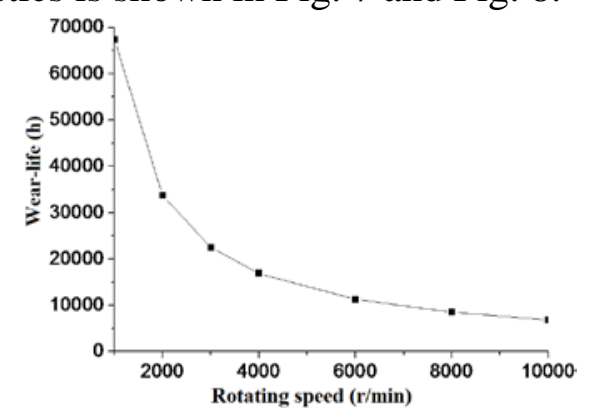

Fig. 7 Relationship between rotating speeds and the wear-life

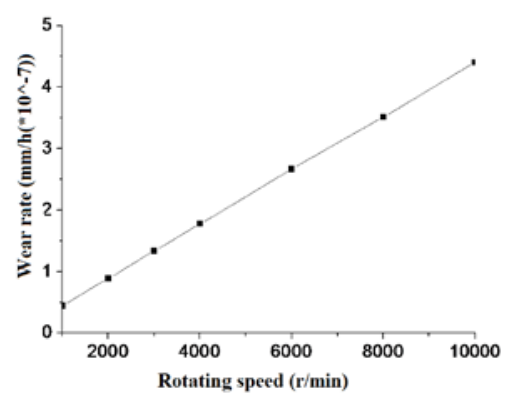

Fig. 8 Relationship between rotating speeds and the wear-rate

It can be seen from Fig. 7 and Fig. 8, when the rotating speed increases, the wear-life decreases non-linearly and the wear-rate increases linearly. With the gradual increase in the rotating speed, the slope of wear-life curve is getting smaller.

\subsection{Influence of the groove curvature of the inner ring}

When the rotating speed is $10000 \mathrm{rpm}$ and the axial load is $20 \mathrm{~N}$, the relation of the groove curvature of the inner ring and wear characteristics is shown in Fig. 9 and Fig. 10.

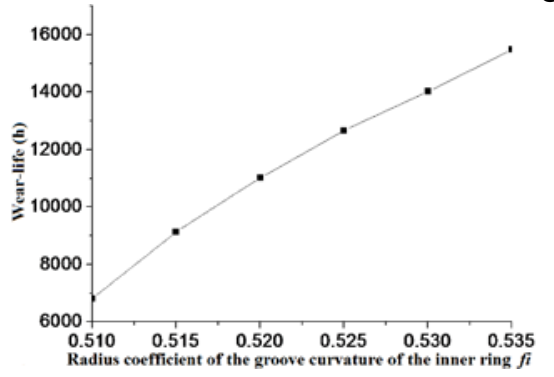

Fig. 9 Relationship between wear-life and groove curvature of the inner ring 


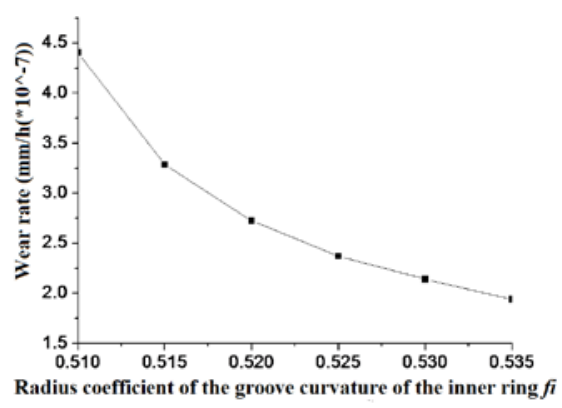

Fig. 10 Relationship between wear-rate and groove curvature of the inner ring

It can be seen from Fig. 9 and Fig. 10, when the groove curvature of the inner ring increases slowly, the wear-life also increases accordingly, while the wear-rate decreases.

\section{CONCLUSION}

The axial load has a great impact on the wear-life of the deep groove ball bearings. When the other factors are fixed, the contact stress between the ball and the race will increase with the axial load accordingly, which will lead to the increase of wear-rate of the race, and the decrease of wear-life. When the axial load is large, the wear-life will decrease slowly and the rate of increase in wear-rate is greater. It is indicated that when the axial load is smaller, it has a greater effect on wear-life.

Similarly, with fixed lubrication condition and other factors, the wear-rate of deep groove ball bearings will increase with the increase of the rotating speed and it basically maintains a linear trend. Since the rotating speed will also affect the micro-sliding between the ball and the race, this leads to the increase of Qu. The wear-life of the bearing will decrease with the increase of the rotating speed, and the slope of the curve is larger at lower rotating speeds, and smaller at higher rotating speed. It is indicated that, when the rotating speed is smaller, it has a greater effect on wear-life.

Finally, with fixed lubrication condition and other factors, when the groove curvature of the inner ring increases, the wear-rate of the deep groove ball bearing decreases. Wear-life decreases with the increase in contract stress caused by the increase of groove curvature of the inner ring. However, the sliding speed at the contact area decreases with the increase of the curvature, this further leads to the decrease of $\mathrm{Qu}$. The wear-life increases slowly with the increase of the curvature. With greater curvature, the slope of the wear-rate curve is smaller.

\section{ACKNOWLEDGMENT}

Thanks for all authors of the references. Special thanks for the members of the research team.

\section{REFERENCES}

[1] Л.К. Precision instrument bearing [M]. National Defense Industry Press, Beijing, China, (1987) (in Chinese).

[2] Tsunodo Kazuo,Suzuki Toshiro. Rolling bearing engineering, Machinery Research and information group, Guizhou, Guiyang, China, (1980) (in Chinese).

[3] S. R. Ge and H. Zhu, Complicate tribological systems and quantitative study methods of their problems, Tribology, 22 (5) (2002) 405-408 (in Chinese).

[4] Y. S. Zhai, A. Li, and J. Z. Zhang, Applied Tribology, China University of Petroleum Press, Shandong, China, (1996) (in Chinese).

[5] J. F. Archard, Contact and rubbing of flat surfaces, Journal of Applied Physics, 24 (8) (1953) 981-988.

[6] C. S. Wan, Analysis method of rolling bearings, China Machine Press, Beijing, China, (1987) 
(in Chinese).

[7] T. A. Harris and M. N. Kotzalas, Rolling Bearing Analysis: Advanced Concepts of Bearing Technology, Fifth Ed. CRC Press (2006).

[8] A. B. Jones, Ball motion and sliding friction in ball bearings, ASME Journal of Basic Engineering, 81 (1) (1959) 1-12.

[9] C. H. Liu, X. Y. Chen, J. M. Gu, S. N. Jiang, and Z. L. Feng, High-speed wear lifetime analysis of instrument ball bearings, Proceedings of the Institution of Mechanical Engineering, Part J: Journal of Engineering Tribology, 223 (3) (2009) 495-510.

[10] J. Y. Liu, T. E. Tallian, and J. I. McCool, Dependence of bearing fatigue life on film thickness to surface roughness ration, ASLE Transactions, 18 (2) (1975) 144-152.

[11] Y. H. Wu and X. Liu, The integrity solutions of mathematical calculation MathCAD 2001, Posts \& Telecom Press, Beijing, China, (2001) (in Chinese).

[12] J. Brändlein, P. Eschmann, L. Hasbargen, and K. Weigand, Ball and Roller Bearings: Theory, Design and Application, Third Ed. Wiley, (1999). 